\title{
1 Factors associated with risk behavior in travelers to tropical and subtropical
}

2 regions.

3

4 Authors: Marta Aldea, MD, MPH ${ }^{\mathrm{a}, *}$, Alberto L. García-Basteiro, MD, MPH ${ }^{\text {a }}$, Jose

5 Muñoz, MD, $\mathrm{PhD}^{\mathrm{b}}$ c , Joaquim Gascón, $\mathrm{MD}, \mathrm{PhD}^{\mathrm{b}} \mathrm{c}$, Edelweiss Aldasoro, $\mathrm{MD}^{\mathrm{b}} \mathrm{c}$,

6 Azucena Bardají, MD, $\mathrm{PhD}^{\mathrm{b}}$ c , Anna Vilella, $\mathrm{MD}, \mathrm{PhD}^{\mathrm{a} \mathrm{b} d}$.

7

$8{ }^{a}$ Preventive Medicine and Epidemiology Department, Hospital Clínic, Villarroel 170,

908036 Barcelona, Spain; ${ }^{b}$ Barcelona Centre for International Health Research

10 (CRESIB, Hospital Clínic-Universitat de Barcelona), Rosselló 132, 08036 Barcelona,

11 Spain; ${ }^{c}$ International Health Centre, Hospital Clínic, Villarroel 170, 08036 Barcelona,

12 Spain; ${ }^{\mathrm{d}}$ Public Health Department, University of Barcelona, Casanova 143, 08036

13 Barcelona, Spain.

14

*Corresponding author:

16 Tel: (0034) 932275400 - Ext. 4131

17 Fax: (0034) 932271866

18 e-mail: $\underline{\text { maldea@ clinic.ub.es }}$

19 Present Adress: Hospital Clínic of Barcelona. Villarroel, 170. 08036, Barcelona.

21 Present address of Alberto L. García-Basteiro: Centro de Investigação em Saúde de 


\section{ABSTRACT}

28 Background: Recent decades have seen a rise in population movements and, therefore, the spread of tropical diseases and changes in the epidemiology of global disease patterns. Only $50 \%$ of travelers to tropical areas receive pre-travel advice and most of

31 them present risk behaviors for acquiring infections. The aim of this study was to

32 describe the clinical and epidemiological characteristics of travelers and identify factors 33 associated with risk behaviors.

34 Methods: We made a retrospective, descriptive and analytical study of 772 travelers consulting a tropical medicine clinic in 2010. Data on demographic and clinical variables, travel characteristics and risk behaviors were collected.

37 Results: $66 \%$ of travelers received pre-travel advice and $31 \%$ took malaria prophylaxis.

38 At least one risk behavior was reported by $82.6 \%$ of travelers. People travelling for 1-6 months had a 3-fold higher likelihood of experiencing risk behaviors than people travelling for $<1$ month $(95 \%$ CI 1.54-5.81, $\mathrm{p}=0.001)$, and those travelling for $>6$ months had a 13-fold higher likelihood (95\%CI 3.11-56.14, $\mathrm{p}<0.001)$ compared with the same group. Increasing age was associated with presenting less risk behaviors.

Conclusions: Younger travelers and those making longer trips have a higher number of risk behaviors. Strategies emphasizing advice on risk behavior should focus on these groups.

Key words: Risk behavior, travel, tropical medicine, emigration and immigration. 


\section{INTRODUCTION}

53 Recent decades have seen an explosion in population movements, mainly due to tourism

54 and migration. It is estimated that, in 2009, international tourist arrivals reached 880

55 million ${ }^{1}$ and new destinations are constantly emerging ${ }^{2}$. In 2010, about 214 million

56 people were living outside their country of birth, representing around 3\% of the world's

57 population ${ }^{3}$. According to the United Nations, $37 \%$ of global migration occurs from

58 developing to developed countries ${ }^{4}$ and Europe receives one in three international

59 migrants ${ }^{3}$.

60 It is estimated that $15-64 \%$ of travelers to tropical and subtropical areas suffer health

61 problems during or after traveling ${ }^{5-7}$. Infections are the leading cause of morbidity ${ }^{8}$,

62 with diarrhea being the most-frequently diagnosed disease (20-60\% of cases) ${ }^{7,}$, .

63 Population movements suppose a risk for both individual and public health, as travel

64 facilitates the spread of infectious diseases from endemic regions. This may involve the

65 reintroduction of infections in previously unexposed populations and an increased

66 incidence of infections already existing in the host countries ${ }^{10-13}$.

67 The risk of illness in travelers varies widely due to factors such as the region visited, the

68 time of year, the length, characteristics and reason for the trip, risk behaviors adopted

69 and individual susceptibility, among others ${ }^{5-8}$. Studies have shown that immigrants

70 living in developed countries who travel to their countries of origin to visit friends and

71 relatives (VFRs) have an increased risk of some diseases, including malaria, HIV,

72 sexually transmitted diseases, tuberculosis and viral hepatitis ${ }^{14-18}$. In most cases, the

73 disease risk can be reduced by preventive measures, underlining the importance of

74 medical advice ${ }^{19}$. Studies have shown that about $50 \%$ of travelers have received pre-

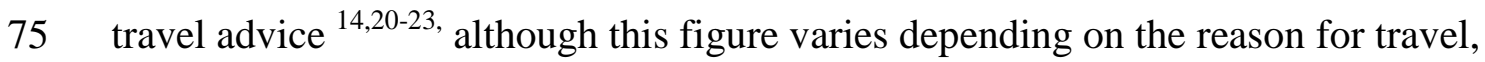

76 ranging from $60-70 \%$ in tourists to around $20 \%$ in VFRs ${ }^{15,17,18}$. It is also estimated that 
77 almost $80 \%$ of travelers do not follow recommendations about food consumption, an

78 important route of disease transmission ${ }^{19}$, and that $4-51 \%$ have casual sexual

79 relationships during their trip, of whom around half do not use condoms ${ }^{7,24-26}$.

80 The aim of this study was to describe the clinical and epidemiological characteristics of

81 travelers to developing countries, and determine the factors associated with risk

82 behaviors.

83

84 MATERIALS AND METHODS

85 We carried out a retrospective descriptive, analytical study of all travelers aged $>18$

86 years attending the Tropical Medicine Unit, Hospital Clínic of Barcelona between

87 January and December 2010, after international travel. Both patients who consulted due

88 to symptoms during and after travel and symptomless patients who came for a check-up

89 were included. Newly-arrived immigrants who attended the Tropical Medicine Unit

90 were not included because, as they were living in tropical and subtropical regions, they

91 were not asked for risk behaviors.

92 The following variables were collected using a computerized form: age, sex, date and

93 reason for consultation, travel characteristics (countries visited, length of trip, reason for

94 trip, date of end of trip), preventive measures, risk behaviors and final diagnosis.

95 The variable reason for consultation was divided into seven categories: fever, diarrhea,

96 skin lesions, eosinophilia (patients referred from another center for evaluation of

97 eosinophilia), asymptomatic check-up and others.

98 The countries visited were grouped into 7 geographical regions, according to the

99 GeoSentinel classification (global travel-related disease-reporting network) ${ }^{20}$, as shown

100 in Figure 1. Patients who had traveled to more than one region were classified as "more 
101 than one region". Travelers to regions other than the study regions (North America,

102 Europe, Russia, Australia and New Zealand) were not included.

103 The length of the trip was categorized into 3 groups ( $\leq 30$ days, $31-179$ days and $\geq 180$

104 days) and the reason for traveling into 5 groups: tourism, business, aid work, VFRs and

105 others.

106 Information was collected on whether travelers had received preventive advice from an

107 accredited vaccination center, whether they had received malaria chemoprophylaxis and

108 whether they had completed the course.

109 Travelers were asked about the following risk behaviors while traveling: Consumption

110 of non-bottled water, local dairy products, raw or undercooked meat or fish, contact

111 with water from rivers or lakes, unsafe sex, blood transfusions, injections with non-

112 disposable material, and contact with soil or mud. From the answers to these questions

113 we created a new dichotomous variable which grouped travelers into those with no risk

114 behaviors and those with one or more risk behaviors, in order to study the associated

115 factors. Transfusions and injections were not included in the new variable as they are

116 involuntary.

117 The final diagnoses are based on microbiological and other tests performed according to

118 clinical indication, and on clinical and epidemiological criteria in cases in which tests

119 were negative. Diagnoses were divided into 31 categories.

120

121 Statistical analysis

122 Quantitative variables were described using the mean and standard deviation in

123 variables with a normal distribution, and median and interquartile range for variables

124 with non-normal distribution. Qualitative variables were described as valid percentages.

125 The reason for traveling was analysed according to the geographic region visited. The 
126 diagnosis was analysed according to the reason for traveling and the reason for

127 consultation. Risk behaviors were analysed according to the reason and length of the

128 trip. In the analysis of the diagnosis, patients were excluded when not all tests requested

129 to reach a diagnosis were performed. Associations between qualitative variables were

130 assessed using the chi-square test or Fisher's exact test. A logistic regression model was

131 constructed to determine the variables associated with presenting one or more risk

132 behaviors. Variables with some degree of association in the bivariate analysis (p-value

133 of Wald test $<0.1$ ) and variables considered relevant according to a priori criteria were

134 included in the multivariate model. All analyses were performed using the SPSS v18

135 statistical package. The study protocol was approved by the Ethics Committee of the

136 Hospital Clínic de Barcelona.

\section{RESULTS}

139 Of all patients seen at the Tropical Medicine Unit during 2010, a total of 1087 patients

140 were initially studied, of whom 308 were excluded because they were newly-arrived

141 immigrants and seven were excluded because they had traveled to regions not included

142 in the study. The final sample consisted of 772 patients: 485 (62.8\%) tourists, 122

$143(15.8 \%)$ business travelers, 96 (12.4\%) aid workers, 45 (5.8\%) VFRs, 15 (1.9\%)

144 travelers for other reasons and $9(1.2 \%)$ travelers with an unknown reason for travel.

145 The mean age (SD) was 37.1 years (11.8) and 43.7\% (337/772) were male, but there

146 was a predominance of males among business travelers (60.7\% [74/122]), and a

147 predominance of females among aid workers (70.8\% [68/96]). The most-visited regions

148 were: Sub-Saharan Africa (35.3\% [268/759]), South Central Asia (17.7\% [134/759])

149 and Central America and Caribbean (14.9\% [113/759]). The median length of the trip

150 (interquartile range) was $21(15$ - 45) days, and was longer in aid workers (60 [30 - 150] 
151 days). The median time between the end of the trip and consultation was $12(5-42)$

152 days. A total of $65.8 \%$ (466/708) of travelers had received pre-travel advice and $30.7 \%$

$153(209 / 680)$ had taken malaria prophylaxis. These percentages were higher in aid workers

154 (78.0\% [71/91] and 50.6\% [44/87], respectively) and markedly lower in VFRs (17.9\%

155 [7/39] and 12.1\% [4/33], respectively). Of those receiving prophylaxis, 27.2\% (47/173)

156 did not complete the course (Table 1).

157 The most-frequent reasons for consultation were diarrhea (35.7\% [274/767]), and fever

$158(22.0 \%$ [169/767]). Figure 2 shows the distribution of reasons for consultation by

159 geographic region visited.

160 A total of 848 diagnoses were made in the 744 patients who underwent all diagnostic

161 tests requested. The most-frequent diagnosis was diarrhea of infectious origin

162 (confirmed and probable) (36.5\% [307/842]), of which 13.0\% (40/307) were parasitic in 163 origin, $11.1 \%(34 / 307)$ bacterial, and $75.6 \%$ (232/307) of unknown origin. Analysis of

164 diagnoses according to the reason for traveling showed that diarrhea was the most-

165 frequent diagnosis in tourists, aid workers and business travelers, followed by non-

166 infectious diseases. In VFRs, the most-frequent diagnoses were non-infectious diseases

$167(20.7 \%[12 / 58])$, diarrhea of infectious origin (19.0\% [11/58]), together with malaria

$168(17.2 \%[10 / 58])$, which accounted for no more than $5 \%$ of diagnoses in all other groups

169 (Table 2). HIV serostatus of the patients was unknown, and of all tests performed by

170 medical indication none were positive.

171 Table 3 shows the most frequent diagnoses according to the reason for consultation. In

172 patients consulting for fever, the most-frequent diagnosis was an arbovirus (dengue $(\mathrm{n}=$

173 31) and Chikungunya $(\mathrm{n}=1), 16.5 \%$ [32/194]), with malaria representing only $10.3 \%$

174 (20/194) of total fever consultations. 
175 At least one risk behavior was reported by $82.6 \%$ (587/711) of travelers. The most-

176 frequent risk behaviors were the consumption of non-bottled water and local dairy

177 products, contact with soil or mud, and with fresh water from rivers or lakes. Table 4

178 shows the percentage of travelers reporting each risk behavior according to the length of

179 the trip, with all percentages increasing in tandem with longer travel time. There were

180 no significant differences when risk behaviors were analysed according to the reason for

181 traveling.

182 Variables associated with one or more risk behaviors in the bivariate analysis and

183 therefore included in the multivariate logistic regression model were age and length of

184 the trip. Likewise, the variable reason for traveling was included because some studies

185 suggest it plays a role in increasing risk behavior in travelers. In the multivariate

186 analysis, the variable length of the trip had the closest association with risk behaviors.

187 People who traveled for 1-6 months had a 3-fold higher likelihood of experiencing risk

188 behavior than those traveling for $<1$ month (OR 2.99, 95\% CI: 1.54 to $5.81, \mathrm{P}=0.001)$

189 and those who traveled for > 6 months had a 13-fold higher likelihood (OR 13.20, 95\%

190 CI: 3.11 to $56.14, \mathrm{P}<0.001)$. Travelers for business reasons were less likely to have

191 risky behaviors than tourists (aOR $0.52,95 \% \mathrm{CI}: 0.29$ to $0.93 ; \mathrm{p}=0.028$ ), while no

192 significant associations were found for other categories of the variable reason for

193 traveling. There was a non-significant trend toward less risk behaviors with age,

194 especially in people aged $>50$ years (Table 5 ).

195 Sex, geographic region visited, reason for traveling and receiving pre-travel advice were

196 not associated with risk behaviors (Table 5).

197

198

199 


\section{DISCUSSION}

201 We determined the characteristics of travelers consulting a Tropical Medicine Clinic

202 and the factors associated with risk behavior during traveling. The results show that the

203 percentage of travelers receiving pre-travel advice was slightly higher than in other

204 studies $^{14,20-23}$, while the percentage receiving malaria chemoprophylaxis was similar to

205 that of other reports $8,16,23,27$. These percentages were lower among VFRs, as found by

206 other authors ${ }^{15-18,27}$. This is particularly relevant if we consider that the main

207 destination for travelers of this type is Sub-Saharan Africa, where malaria is endemic.

208 On the other hand, it seems that VFRs receiving chemoprophylaxis complete it in

209 similar proportions to tourists.

210 The low perception of risk among VFRs, shown by the smaller number seeking medical

211 advice, is one of the main factors in the increased risk of disease in this group. As

212 previously reported ${ }^{14-18}$, we also observed a higher proportion of cases of malaria

213 among VFRs compared with other groups. Studies suggest that other factors influencing

214 increased susceptibility in VFRs may include the wide age-range (including infants and

215 the elderly, who are more susceptible to illness) and living in the same conditions as the

216 local population in the countries of origin visited ${ }^{28-31}$.

217 Conversely, we did not find that VFRs had more risk behaviors than other groups of

218 travelers for the variables studied. However, we did not study the use of mosquito nets

219 or mosquito repellent, which are the malaria-related behaviors. A possible explanation

220 could be that, living in developed countries, VFRs acquire hygienic and alimentary

221 habits that place them in the same situation as other groups of travelers with respect to

222 risk behaviors. However, the small number of VFRs in the study population hinders

223 results' interpretation. 
224 Independently of the reason for traveling, more than $80 \%$ of travelers reported one or

225 more risk behaviors during the trip, a percentage similar to other studies ${ }^{19}$. However,

226 this percentage could be higher, because we haven't taken into account other risk

227 behaviours such as the consumption of salads or uncooked vegetables, as it was not

228 registered in the clinical records of the patients. Moreover, we have to take into account

229 that adopting non-risky behaviours does not always mean having no risk. An example

230 would be drinking bottled water, that sometimes may not be safe.

231 The length of the trip was the factor that most-influenced the presence of risk behaviors.

232 People traveling for more than one month had a 3-fold higher likelihood of risk

233 behavior, and those traveling for more than 6 months a 13-fold higher likelihood. This

234 may reflect the difficulty of maintaining desirable behaviors that may require an effort

235 over time. There was also a trend to less risk behavior with greater age, as reported by

236 other studies ${ }^{19,32}$, and in people traveling on business compared with tourists, possibly

237 because business travelers have less leisure time and less contact with the local

238 population.

239 Unexpectedly, receiving preventive advice before traveling had no effect on risk

240 behavior. This could be due to the difficulty in changing behavior despite

241 recommendations ${ }^{33}$. However, these results also suggest that preventive advice

242 probably concentrates on vaccination and malaria prophylaxis, with less emphasis on

243 advice about risk behavior.

244 We also found that dengue was the main cause of fever in the study population and not

245 malaria, as reported by other studies ${ }^{14,16,20,21}$. A possible explanation is the steep rise in

246 cases of Dengue fever in the last decade, especially in South and Southeast Asia, and

247 the Pacific West (regions which accounted for almost $60 \%$ of the cases of Dengue fever

248 found in this study), but also in South America ${ }^{34-36}$. 
Limitations

250 One limitation of the study is that patients attended by the Tropical Medicine Clinic may not be representative of all travelers to developing countries. Firstly, travelers

252 without health problems are not represented, unless they attend for a check-up.

253 Secondly, some travelers may consult their general practitioner, and if there is no

254 referral to a specialist it is probably because any disease is mild and self-limiting.

255 Therefore, in our population, travelers with mild disease are probably underrepresented, 256 as are those who had diseases with a short incubation period that occurred during the 257 trip.

CONCLUSIONS

260 The reason for traveling is an important factor in the decision to seek travel advice and

261 take malaria prophylaxis. VFRs seem to have a lower perception of the risks of

262 traveling to tropical areas. This underlines the importance of all travelers being aware of

263 the risks they face and the need to seek medical advice.

264 Younger travelers and those making longer trips have a higher number of risk

265 behaviors. Medical advice does not seem to influence risk behavior, and therefore new

266 strategies of health promotion may be needed that place greater emphasis on healthy

267 behaviors.

269 Authors' contributions

270 MA, AV and JM conceived the study. MA designed the study protocol which was reviewed by ALGB, AV and JM. JM, JG, EA and AB carried out the clinical assessment. MA carried out the analysis and interpretation of the data, and drafted the manuscript. ALGB and AV critically revised the manuscript for intellectual content. All 
274 authors read and approved the final manuscript. MA and AV are the guarantors of the

275 paper.

276 Acknowledgements

277 We thank the hospital archive staff for providing medical records, Higini Cortés for

278 helping with data processing, and Anna Llupià, Guillermo Mena and Víctor Guillermo

279 Sequera for their support.

280 Funding

281 The study was conducted with no funding, but CRESIB Research group receives funds

282 from the Agència de Gestió d'Ajuts Universitaris i de Recerca (AGAUR),

283 2009SGR385.

284 Competing interests

285 The authors declare they have no conflicts of interest.

286 Ethical approval

287 The study procedures were in accordance with the ethical standards of the Helsinki

288 Declaration and the protocol was approved by the Ethics Committee of the Hospital

289 Clínic of Barcelona.

290

291

292

293

294

295

296

297

298 
300 1. UNWTO (World Tourism Organization). UNWTO Tourism Highlights. 2010.

301 http://www.unwto.org/facts/menu.html [accessed June 2010].

302 2. UNWTO (World Tourism Organization). Historical perspective of world tourism.

303 2005. http://www.unwto.org/facts/eng/historical.htm [accessed June 2010].

304 3. IOM (International Organization for Migration). World Migration Report 2010. The 305 future of migration: Building capacities for change.

306 http://publications.iom.int/bookstore/free/WMR_2010_ENGLISH.pdf [accessed June

307 2010].

308 4. UNDP (United Nations Development Programme). Human development report 2009.

309 http://hdr.undp.org/en/media/HDR_2009_EN_Chapter2.pdf [accessed June 2010].

310 5. Steffen R, Rickenbach M, Wilhelm U et al. Health problems after travel to

311 developing countries. J Infect Dis 1987;156:84-91.

312 6. Hill DR. Health problems in a large cohort of Americans traveling to developing

313 countries. J Travel Med 2000;7:259-66.

314 7. Steffen R, deBernardis C, Banos A. Travel epidemiology--a global perspective. Int J

315 Antimicrob Agents 2003;21:89-95.

316 8. Zamarron Fuertes P, Perez-Ayala A, Perez Molina JA et al. Clinical and

317 epidemiological characteristics of imported infectious diseases in Spanish travelers. J

318 Travel Med 2010;17:303-9.

319 9. Gascon J, Ruiz L, Canela J et al. [Epidemiology of traveler's diarrhea in Spanish

320 tourists travelling in developing countries]. Med Clin (Barc) 1993;100:365-7.

321 10. Angelini R, Finarelli AC, Angelini P et al. An outbreak of chikungunya fever in the 322 province of Ravenna, Italy. Euro Surveill 2007;12:E070906.1.

323 11. Fortun J, Martin-Davila P, Navas E et al. Changes in the epidemiology of 324 tuberculosis: the influence of international migration flows. Enferm Infecc Microbiol 325 Clin 2011;29:654-9.

326 12. Monge-Maillo B, Jimenez BC, Perez-Molina JA et al. Imported infectious diseases 327 in mobile populations, Spain. Emerg Infect Dis 2009;15:1745-52.

328 13. Bueno Mari R, Jimenez Peydro R. [Could malaria and dengue reappear in Spain?].

329 Gac Sanit 2010;24:347-53.

330 14. Ansart S, Perez L, Vergely O et al. Illnesses in travelers returning from the tropics: a 331 prospective study of 622 patients. J Travel Med 2005;12:312-8. 
332 15. Gautret P, Schlagenhauf P, Gaudart J et al. Multicenter EuroTravNet/GeoSentinel 333 study of travel-related infectious diseases in Europe. Emerg Infect Dis 2009;15:178333490.

335 16. Bottieau E, Clerinx J, Schrooten W et al. Etiology and outcome of fever after a stay 336 in the tropics. Arch Intern Med 2006;166:1642-8.

337 17. Fenner L, Weber R, Steffen R, Schlagenhauf P. Imported infectious disease and 338 purpose of travel, Switzerland. Emerg Infect Dis 2007;13:217-22.

339 18. Leder $\mathrm{K}$, Tong S, Weld $\mathrm{L}$ et al. Illness in travelers visiting friends and relatives: a 340 review of the GeoSentinel Surveillance Network. Clin Infect Dis 2006;43:1185-93.

341 19. Rack J, Wichmann O, Kamara B et al. Risk and spectrum of diseases in travelers to 342 popular tourist destinations. J Travel Med 2005;12:248-53.

343 20. Freedman DO, Weld LH, Kozarsky PE et al. Spectrum of disease and relation to 344 place of exposure among ill returned travelers. N Engl J Med 2006;354:119-30.

345 21. Field V, Gautret P, Schlagenhauf $\mathrm{P}$ et al. Travel and migration associated infectious 346 diseases morbidity in Europe, 2008. BMC Infect Dis 2010;10:330.

347 22. Van Herck K, Van Damme P, Castelli F et al. Knowledge, attitudes and practices in 348 travel-related infectious diseases: the European airport survey. J Travel Med 2004;11:33498.

350 23. Hamer DH, Connor BA. Travel health knowledge, attitudes and practices among 351 United States travelers. J Travel Med 2004;11:23-6.

352 24. Fricker M, Steffen R. Travel and public health. J Infect Public Health 2008;1:72-7.

353 25. Croughs M, Van Gompel A, de Boer E, Van Den Ende J. Sexual risk behavior of 354 travelers who consulted a pretravel clinic. J Travel Med 2008;15:6-12.

355 26. Velasco M, Morote S, Aramburu C et al. [Sexual behavior risk in Spanish

356 international travelers]. Med Clin (Barc) 2001;116:612-3.

357 27. Antinori S, Galimberti L, Gianelli E et al. Prospective observational study of fever 358 in hospitalized returning travelers and migrants from tropical areas, 1997-2001. J Travel 359 Med 2004;11:135-42.

360 28. Neave PE, Jones CO, Behrens RH. A review of risk factors for imported malaria in 361 the European African diaspora. J Travel Med 2010;17:346-50.

362 29. Rojo Marcos G, Cuadros Gonzalez J, Arranz Caso A. [Imported infectious diseases 363 in Spain]. Med Clin (Barc) 2008;131:540-50.

364 30. Valerio L, Roure S, Rubiales A et al. [Imported infectious diseases associated with 365 international trips by adult immigrants to visit family and friends]. Gac Sanit 2009;23 366 Suppl 1:86-9. 
367 31. Ryan ET, Wilson ME, Kain KC. Illness after international travel. N Engl J Med 368 2002;347:505-16.

369 32. Alon D, Shitrit P, Chowers M. Risk behaviors and spectrum of diseases among 370 elderly travelers: a comparison of younger and older adults. J Travel Med 2010;17:2503715.

372 33. Bellamy R. An introduction to patient education: theory and practice. Med Teach 373 2004;26:359-65.

374 34. WHO (World Health Organization). Dengue and dengue haemorrhagic fever. Fact 375 sheet $\mathrm{N}^{\circ}$ 117. 2009. http://www.who.int/mediacentre/factsheets/fs 117/en/ [accessed 376 June 2010].

377 35. San Martin JL, Brathwaite O, Zambrano B et al. The epidemiology of dengue in the 378 americas over the last three decades: a worrisome reality. Am J Trop Med Hyg $3792010 ; 82: 128-35$.

380 36. TropNetEurop. TropNetEurop Sentinel Surveillance Report: May 2010. Dengue381 fever in 2009. 2010.

382

383

384

385

386

387

388

389

390 


\section{TABLES}

Table 1. Epidemiological characteristics of the study population according to the reason for traveling $(\mathrm{N}=763)^{\mathrm{a}}$.

\begin{tabular}{|c|c|c|c|c|c|}
\hline Variable & $\begin{array}{l}\text { Tourism } \\
(n=485)\end{array}$ & $\begin{array}{c}\text { Business } \\
(n=122)\end{array}$ & $\begin{array}{c}\text { Aid work } \\
(\mathrm{n}=96)\end{array}$ & $\begin{array}{c}\text { VFRs } \\
(n=45)\end{array}$ & $\begin{array}{l}\text { Others } \\
(n=15)\end{array}$ \\
\hline Sex (n,\% male) & $209(43.1)$ & $74(60.7)$ & $28(29.2)$ & $19(42.2)$ & $2(13.3)$ \\
\hline \multicolumn{6}{|l|}{ Age (years) } \\
\hline Mean & 36.7 & 39.1 & 34.4 & 38.6 & 45.3 \\
\hline Standard deviation & 11.6 & 10.2 & 13.8 & 11.9 & 11.8 \\
\hline \multicolumn{6}{|l|}{ Geographic region visited $(n, \%)$} \\
\hline Central America and Caribbean & $73(15.2)$ & $17(14)$ & $17(17.9)$ & $5(11.4)$ & 0 \\
\hline South America & $46(9.6)$ & $12(9.9)$ & $8(8.4)$ & $18(40.9)$ & $4(30.8)$ \\
\hline Mediterranean and Middle East & $28(5.8)$ & $7(5.8)$ & $1(1.1)$ & 0 & 0 \\
\hline Sub-Saharan Africa & $124(25.9)$ & $61(50.4)$ & $56(58.9)$ & $19(43.2)$ & $6(46.2)$ \\
\hline South-Central Asia & $105(21.9)$ & $13(10.7)$ & $10(10.5)$ & $2(4.5)$ & $3(23.1)$ \\
\hline Southeast Asia & $84(17.5)$ & $5(4.1)$ & $1(1.1)$ & 0 & 0 \\
\hline Other & $5(1)$ & $2(1.7)$ & 0 & 0 & 0 \\
\hline More than one region & $14(2.9)$ & $4(3.3)$ & 2.2 .1 & 0 & 0 \\
\hline \multicolumn{6}{|l|}{ Travel time (days) } \\
\hline Median & 20 & 33 & 60 & 32 & 37.5 \\
\hline Interquartile range & $15-28$ & $10-185$ & $30-150$ & $27-60$ & $16,5-112,5$ \\
\hline \multicolumn{6}{|c|}{ Time between end of trip and consultation (days) } \\
\hline Median & 12.5 & 9 & 14 & 14 & 14.5 \\
\hline Interquartile range & $5-43$ & $4-31$ & $4-42$ & $6-67$ & $6,25-126$ \\
\hline Advice to travelers ( $n, \%$ yes) & $310(68.6)$ & $68(60.7)$ & $71(78)$ & $7(17.9)$ & $6(75)$ \\
\hline Malaria prophylaxis ( $\mathrm{n}, \%$ yes) & $129(29.4)$ & $29(26.9)$ & $44(50.6)$ & $4(12.1)$ & $3(37.5)$ \\
\hline \multicolumn{6}{|l|}{ Prophylaxis completed } \\
\hline Yes & $67(62.6)$ & $12(50)$ & $18(48.6)$ & $2(66.7)$ & $1(50)$ \\
\hline Still taking & $16(15)$ & $7(29.2)$ & 3 (8.1\%) & 0 & 0 \\
\hline No & $24(22.4)$ & $5(20.8)$ & $16(43.2)$ & 1 (33.3) & $1(50)$ \\
\hline
\end{tabular}

${ }^{a}$ Information on the reason for traveling was available in 763 of the 772 subjects included in the study. 
Table 2. Distribution of etiologic diagnoses in travelers consulting a tropical medicine clinic according to the reason for traveling $(\mathrm{N}=842)$.

\begin{tabular}{|c|c|c|c|c|c|c|}
\hline Diagnosis & $\begin{array}{l}\text { Tourism } \\
(\mathrm{n}=518)\end{array}$ & $\begin{array}{l}\text { Business } \\
(n=138)\end{array}$ & $\begin{array}{l}\text { Aid work } \\
(n=108)\end{array}$ & $\begin{array}{c}\text { VFRs } \\
(n=58)\end{array}$ & $\begin{array}{l}\text { Others } \\
(n=20)\end{array}$ & $\begin{array}{c}\text { TOTAL } \\
(\mathrm{N}=842)^{a}\end{array}$ \\
\hline Parasitic diarrhea & $23(4.4)$ & $7(5.1)$ & $9(8.3)$ & $1(1.7)$ & 0 & $40(4.8)$ \\
\hline Bacterial diarrhea & $27(5.2)$ & $4(2.9)$ & $1(0.9)$ & 0 & $2(10.0)$ & $34(4.0)$ \\
\hline $\begin{array}{l}\text { Other infectious } \\
\text { diarrhea }\end{array}$ & $1(0.2)$ & 0 & 0 & 0 & 0 & $1(0.1)$ \\
\hline $\begin{array}{l}\text { Diarrhea of probable } \\
\text { infectious origin }\end{array}$ & $151(29.2)$ & $39(28.3)$ & $28(25.9)$ & $10(17.2)$ & $4(20.0)$ & $232(27.6)$ \\
\hline Malaria & $7(1.4)$ & $6(4.3)$ & $2(1.9)$ & $10(17.2)$ & $1(5.0)$ & $26(3.1)$ \\
\hline Arboviruses & $33(6.4)$ & $5(3.6)$ & $2(1.9)$ & $5(8.6)$ & $2(10.0)$ & $47(5.6)$ \\
\hline $\begin{array}{r}\text { Typhoid fever / } \\
\text { paratyphoid }\end{array}$ & $1(0.2)$ & $1(0.7)$ & $1(0.9)$ & 0 & 0 & $3(0.4)$ \\
\hline Rickettsiosis & $3(0.6)$ & 0 & 0 & 0 & $1(5.0)$ & $4(0.5)$ \\
\hline Chagas' disease & 0 & 0 & 0 & 0 & $1(5.0)$ & $1(0.1)$ \\
\hline Intestinal nematodes & $6(1.2)$ & $1(0.7)$ & 0 & 0 & 0 & $7(0.8)$ \\
\hline Other nematodes & $9(1.7)$ & $2(1.4)$ & $2(1.9)$ & 0 & 0 & $13(1.5)$ \\
\hline Cestodes & 0 & $2(1.4)$ & 0 & $1(1.7)$ & $1(5.0)$ & $4(0.5)$ \\
\hline Trematodes & $3(0.6)$ & $2(1.4)$ & 0 & $2(3.4)$ & 0 & $7(0.8)$ \\
\hline Hepatitis & $2(0.4)$ & $1(0.7)$ & $1(0.9)$ & $1(1.7)$ & 0 & $5(0.6)$ \\
\hline $\begin{array}{l}\text { Respiratory tract } \\
\text { infection }\end{array}$ & $26(5.0)$ & $5(3.6)$ & $4(3.7)$ & $2(3.4)$ & 0 & $37(4.4)$ \\
\hline Pneumonia & $9(1.7)$ & $2(1.4)$ & $2(1.9)$ & 0 & 0 & $13(1.5)$ \\
\hline Other viral infections & $23(4.4)$ & $6(4.3)$ & $2(1.9)$ & $2(3.4)$ & $1(5.0)$ & $34(4.0)$ \\
\hline H. pylori infection & $10(1.9)$ & $3(2.2)$ & $3(2.8)$ & $2(3.4)$ & $2(10.0)$ & $20(2.4)$ \\
\hline Bacterial skin infection & $16(3.1)$ & $1(0.7)$ & $1(0.9)$ & $2(3.4)$ & 0 & $20(2.4)$ \\
\hline Superficial mycoses & $2(0.4)$ & $2(1.4)$ & $1(0.9)$ & 0 & 0 & $5(0.6)$ \\
\hline Ectoparasites & $5(1.0)$ & $2(1.4)$ & $1(0.9)$ & 0 & 0 & $8(1.0)$ \\
\hline Insect bite & $23(4.4)$ & $5(3.6)$ & $3(2.8)$ & $1(1.7)$ & 0 & $32(3.8)$ \\
\hline Animal bite & $7(1.4)$ & $1(0.7)$ & 0 & $1(1.7)$ & 0 & $9(1.1)$ \\
\hline Fever of unknown origin & $27(5.2)$ & $2(1.4)$ & $2(1.9)$ & $1(1.7)$ & 0 & $32(3.8)$ \\
\hline $\begin{array}{l}\text { Eosinophilia of } \\
\text { unknown origin }\end{array}$ & $2(0.4)$ & $1(0.7)$ & 0 & 0 & 0 & $3(0.4)$ \\
\hline No pathology & $40(7.7)$ & $17(12.3)$ & $20(18.5)$ & $1(1.7)$ & $2(10.0)$ & $80(9.5)$ \\
\hline $\begin{array}{l}\text { Other infectious } \\
\text { diseases }\end{array}$ & $5(1.0)$ & $4(2.9)$ & 0 & $4(6.9)$ & 0 & $13(1.5)$ \\
\hline $\begin{array}{l}\text { Other non-infectious } \\
\text { diseases }\end{array}$ & $57(11.0)$ & $17(12.3)$ & $23(21.3)$ & $12(20.7)$ & $3(15.0)$ & $112(13.3)$ \\
\hline
\end{tabular}

${ }^{\text {a }}$ Information on the reason for travelling was available for 842 of the 848 diagnoses. 
Table 3. Most frequent diagnoses according to the reason for consultation in travelers attended by a tropical medicine clinic $(\mathrm{N}=843)^{\mathrm{a}}$.

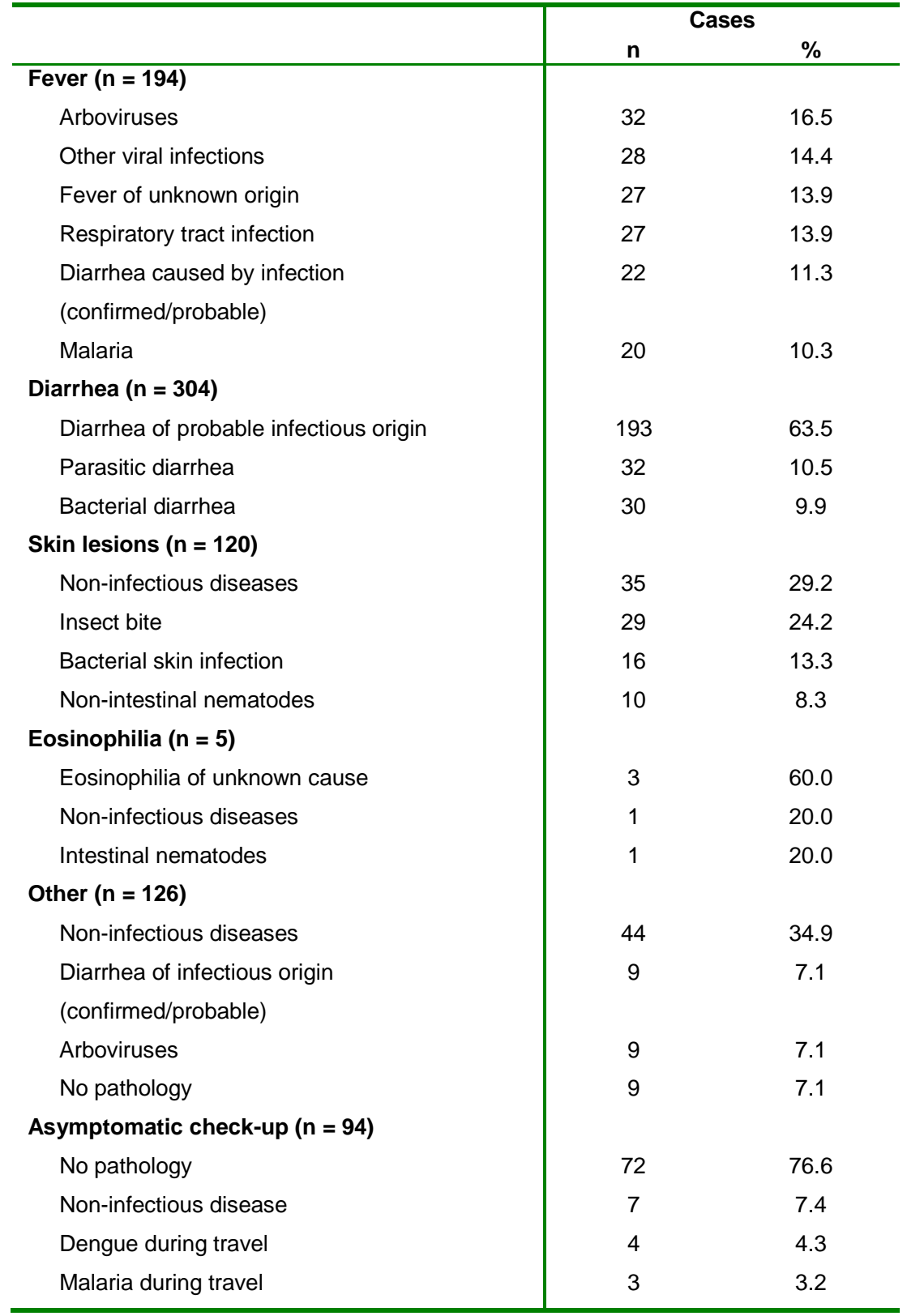

${ }^{\text {a }}$ Information on the reason for consultation was available in 843 of the 848 diagnoses. 
Table 4. Percentage of travelers presenting each risk behaviour according to the length of the trip $(\mathrm{N}=695)$.

\begin{tabular}{|c|c|c|c|c|c|}
\hline Risk behavior & $\begin{array}{c}\leq 30 \text { days } \\
(n=491)\end{array}$ & $\begin{array}{c}\text { 31-179 days } \\
(n=126)\end{array}$ & $\begin{array}{c}\geq 180 \text { days } \\
\quad(n=78)\end{array}$ & $\begin{array}{l}\text { TOTAL }^{\mathrm{a}} \\
(\mathrm{N}=695)^{\mathrm{b}}\end{array}$ & $\begin{array}{c}\text { p-value } \\
\text { (Fischer) }\end{array}$ \\
\hline Consumption of non- bottled water or ice & $232(47.3)$ & $87(69.3)$ & $63(80.8)$ & $382(55.0)$ & $<0.001$ \\
\hline Consumption of local dairy products & $141(28.9)$ & $59(47.2)$ & $46(59.0)$ & $246(35.6)$ & $<0.001$ \\
\hline Consumption of raw or undercooked meat & $39(8.0)$ & $7(5.6)$ & $20(25.6)$ & $66(9.6)$ & $<0.001$ \\
\hline Consumption of raw or marinated fish & $68(14.0)$ & $22(17.6)$ & $27(34.6)$ & $117(17.0)$ & 0.001 \\
\hline Contact with fresh river/lake water & $112(23.1)$ & 49 (39.2) & $40(51.9)$ & $201(29.3)$ & $<0.001$ \\
\hline Risk sex & $11(2.4)$ & $9(7.4)$ & $12(15.8)$ & $32(4.8)$ & $<0.001$ \\
\hline Blood transfusions & $1(0.2)$ & $1(0.8)$ & $1(1.3)$ & $3(0.4)$ & NS \\
\hline Injections with non-disposable material & $14(2.9)$ & $6(4.8)$ & $13(16.9)$ & $33(4.8)$ & $<0.001$ \\
\hline Contact with soil or mud & $154(31.8)$ & $66(52.8)$ & $45(59.2)$ & $265(38.6)$ & $<0.001$ \\
\hline
\end{tabular}

${ }^{a}$ Percentage of total travelers who presented each risk behavior. These percentages do not total $100 \%$ as a single traveler may report more than one risk behavior.

${ }^{\mathrm{b}}$ Information on travel time and risk behavior was available in 695 of all nonimmigrant travelers (772).

NS. Non-significant. 
Table 5. Bivariate and multivariate analysis of factors associated with having presented at least one risk behavior during the trip.

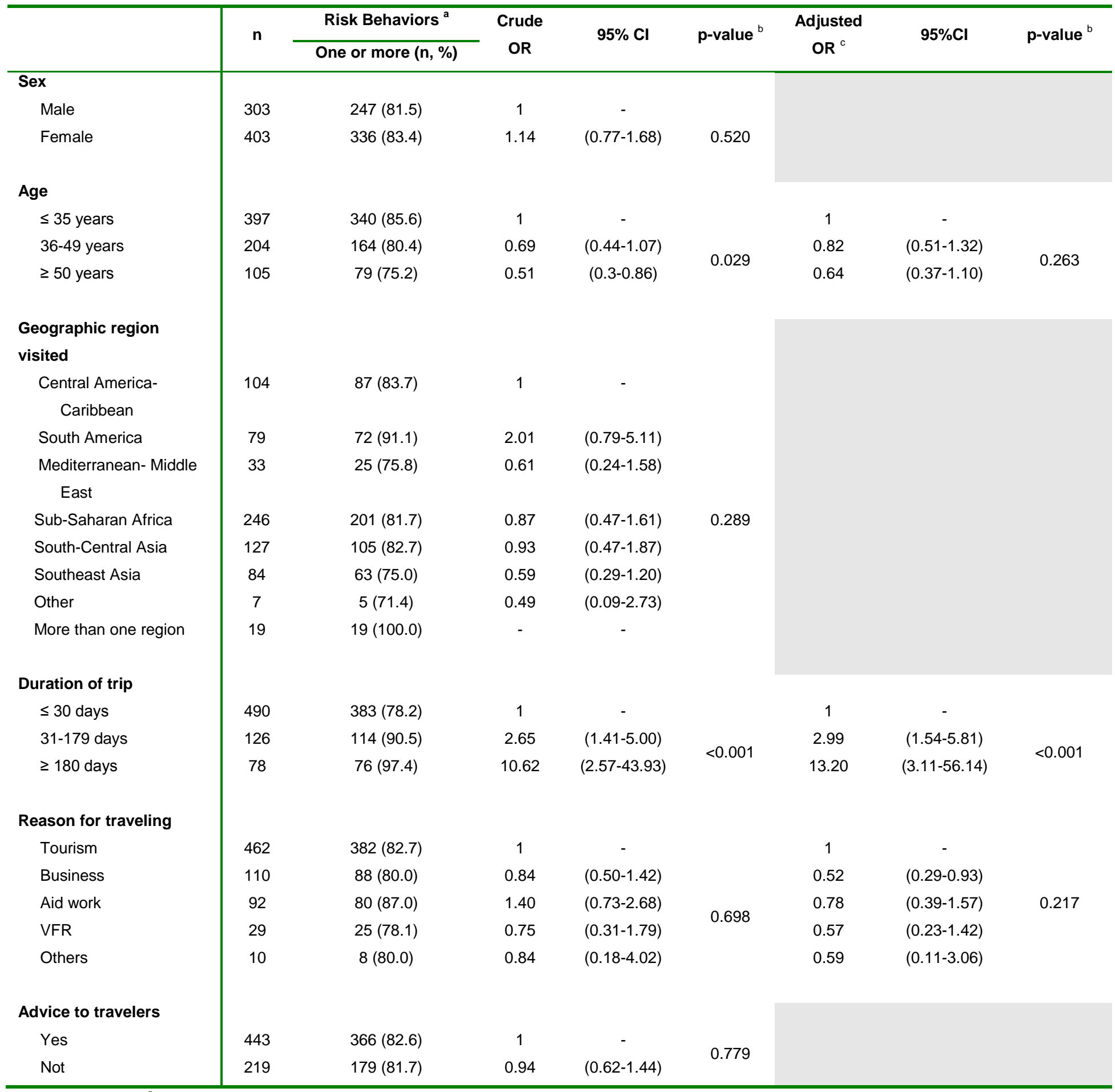

${ }^{\mathrm{a}}$ Includes the consumption of non-bottled water, local dairy products, undercooked or raw meat or fish, exposure to fresh water in lakes and rivers, with earth or mud and unsafe sex.

${ }^{\mathrm{b}} \mathrm{P}$ value calculated by the Wald test.

${ }^{c}$ ORs adjusted for the variables age, duration and reason for trip. 694 subjects included in the multivariate analysis. 
FIGURE CAPTIONS

Figure 1. Geographical distribution of the regions visited by travelers $(N=759)^{a}$.

Footnote: ${ }^{a}$ Information on the geographic region visited was available in 759 of the 772 subjects included in the study.

Figure 2. Distribution of the reason for consultation in travelers attending a tropical medicine clinic according to geographic area visited $(N=756)^{a}$.

Footnote: ${ }^{\text {a }}$ Information on the geographic region visited and the reason for consultation was available in 756 of the 772 subjects included in the study. 
Figure 1.
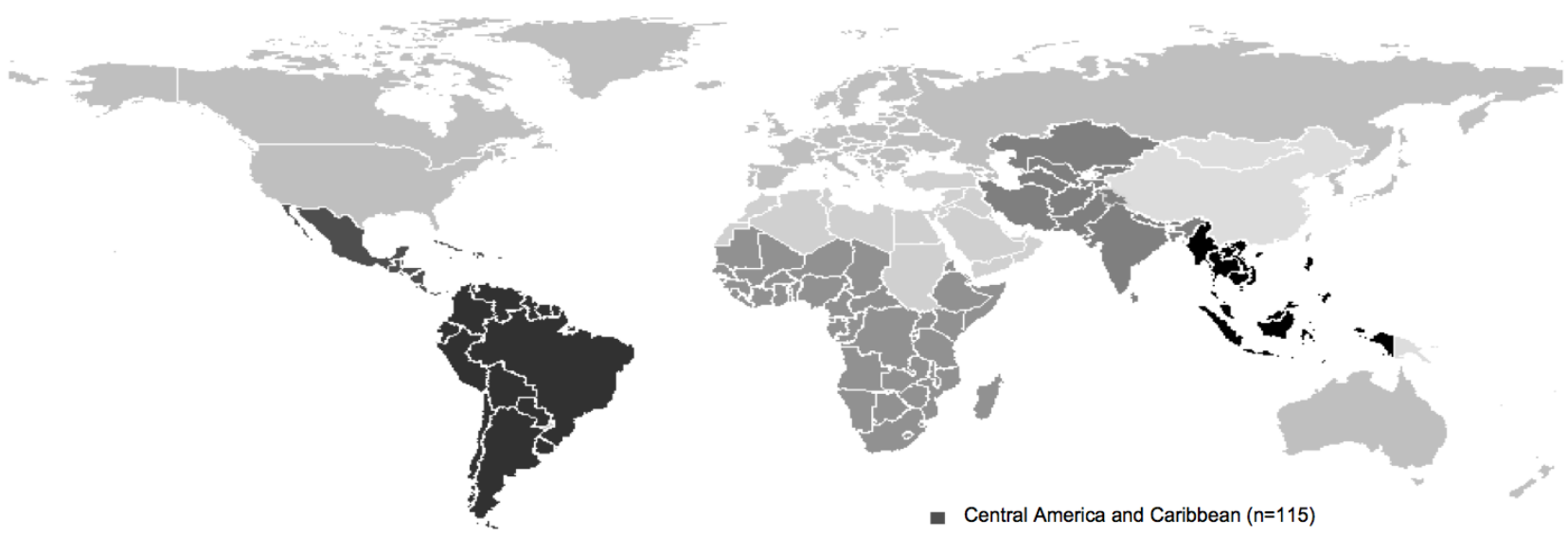

- Central America and Caribbean $(n=115)$

- South America $(n=358)$

- Mediterranean and Middle East $(n=39)$

- Sub-Saharan Africa $(n=285)$

- South and Central Asia $(n=139)$

- Southeast Asia ( $n=91$ )

Others (Northeast Asia, Pacific Islands) $(n=8)$

More than one region $(n=20)$ 
Figure 2.

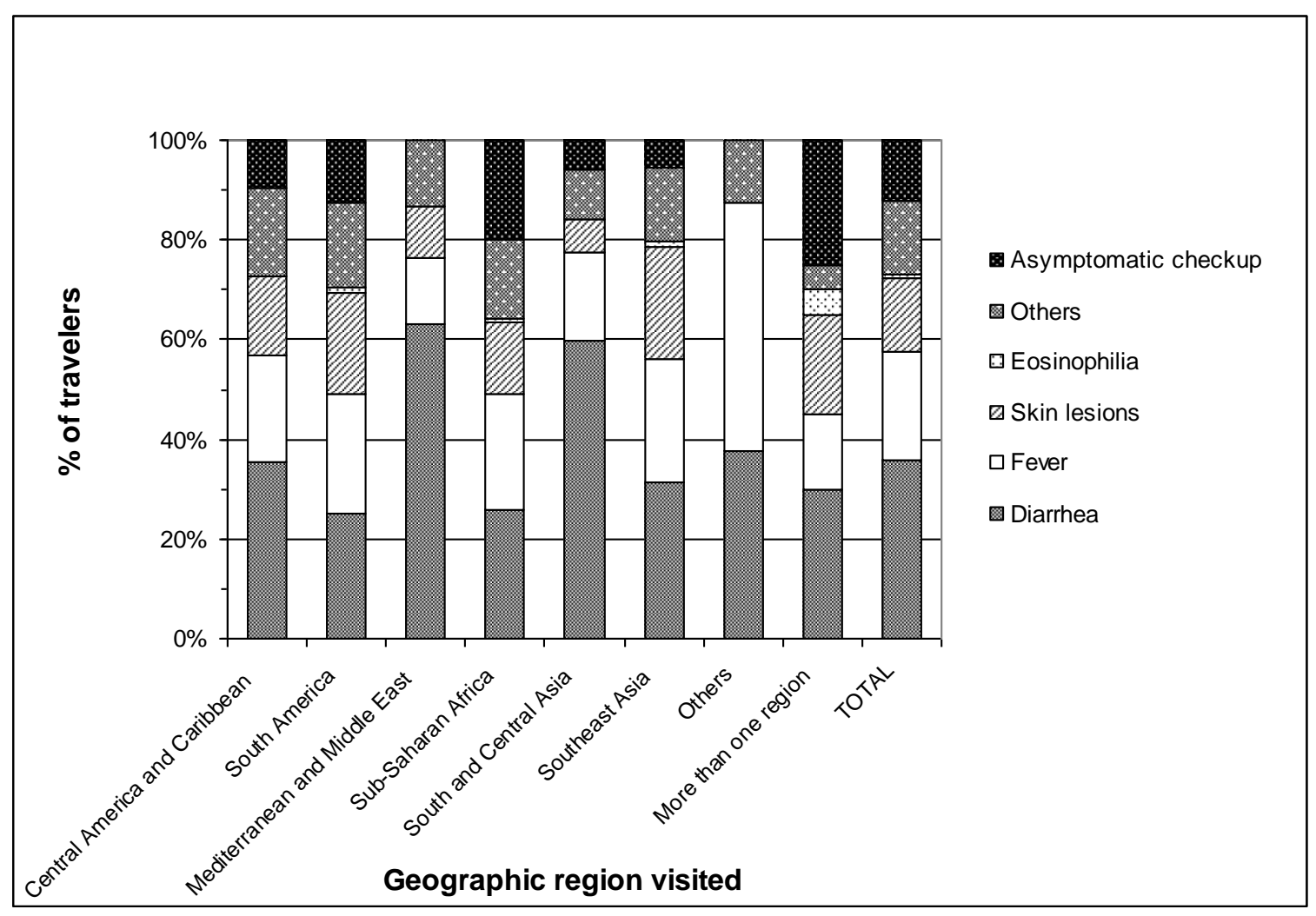




\section{Figure 1}

Click here to download high resolution image

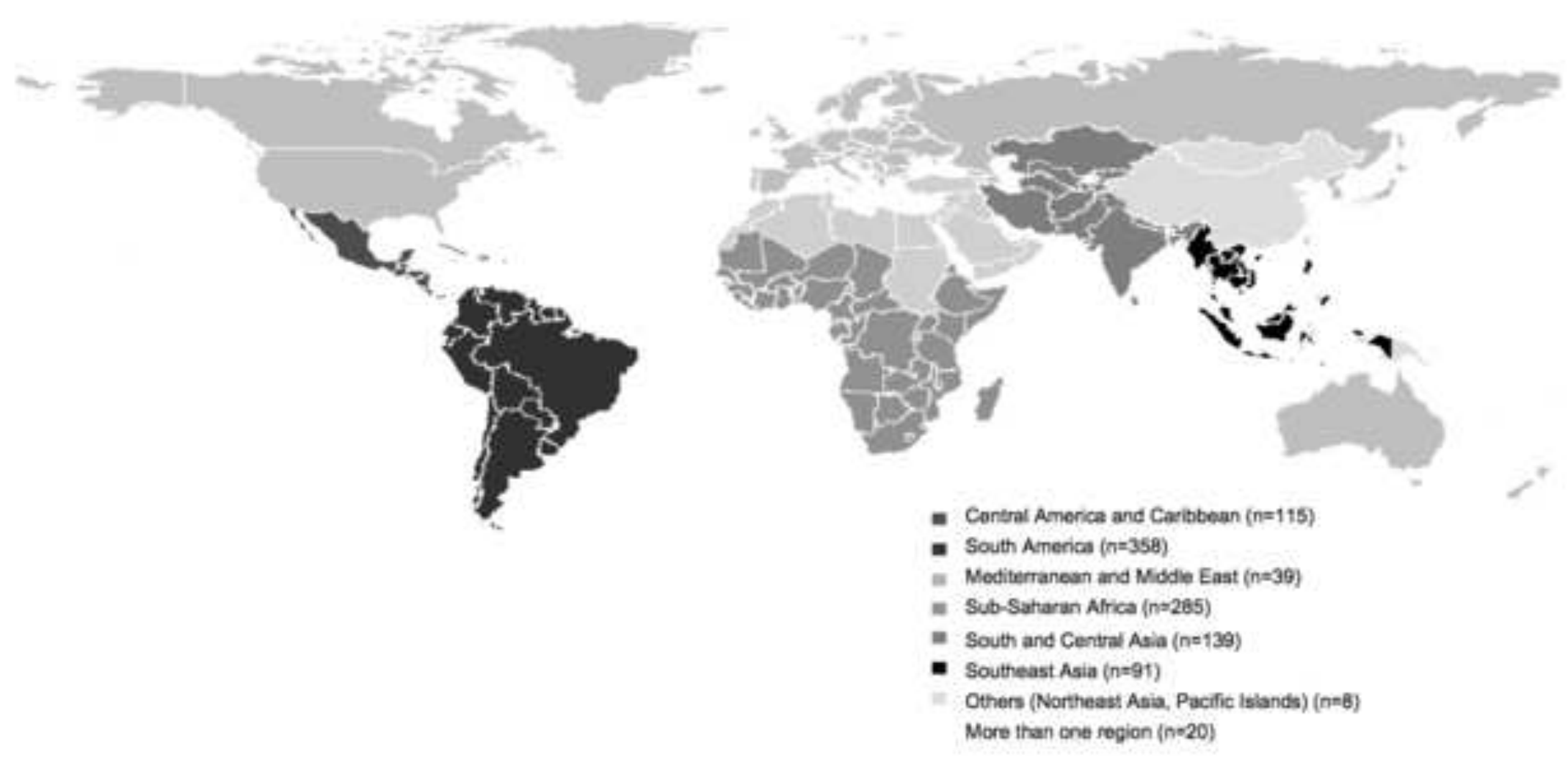




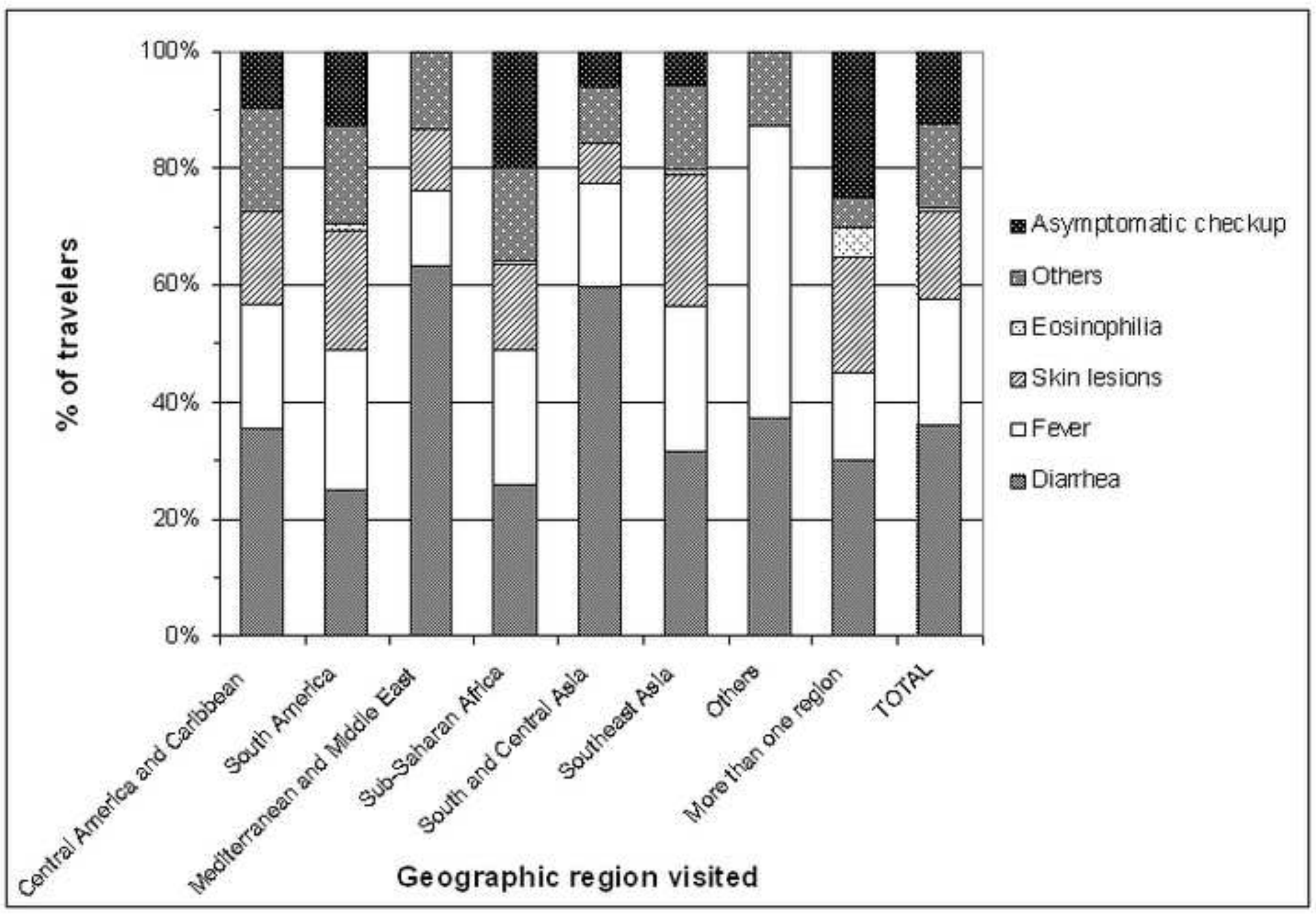

